\title{
ANAIISIS
}

\section{Critical care outreach}

\section{comes to Canada}

$\mathrm{N}$ ot all patients who need care in a high-dependency unit (HDU) are transferred in a timely manner. Such delays may cause the patient to undergo physiological deterioration, prolongation of stay or a less favourable outcome. To avoid such results, the concept of a critical care outreach or medical emergency team $(M E T)^{1}$ was conceived in Australia in I990, and has since become popular there and in the United Kingdom. Its key components are twofold: earlier recognition of a deteriorating patient based on vital signs, and subsequent response and evaluation by a designated team with expertise, experience and resources.

Up to $84 \%$ of inpatients not in an intensive care unit (ICU) who experience cardiac arrest have been found to exhibit an easily detected physiologic instability of their respiratory (the most common) or pulse rate and abnormal oxyhemoglobin saturation before the arrest. ${ }^{2}$ Caregivers often fail to appreci- ate the import of such changes, and take inadequate or no action to prevent further deterioration. One retrospective study $^{3}$ of patients transferred to the ICU found that for $36 \%$ of subjects, care before transfer was suboptimal, with inappropriate treatment or nonrecognition of the severity of their problem. More such ICU patients died in hospital than transferred patients whose advance care was adequate $(65 \%$ v. $42 \%, p<0.00 I)$. In these studies the importance of vitalsign abnormalities was unrecognized, perhaps because of staffing inadequacies: provider inexperience, insufficient appropriate education, lack of adequate supervision, or patient volume overload.

Many of these problems could be remedied by education and recruitment. Restoration of physician and especially nursing staffing levels, however, is expensive and would take years even if appropriate trainees attracted to nursing were sufficiently available. New graduates are inexperienced and require several years to accumulate the experience base of senior nurses. HDUs can provide enhanced care for patients identified as being at risk (e.g., those recently discharged from the ICU or intermediate-acuity patients), but hospital space is required; construction costs may be incurred; and although operating expenses of HDUs are less than those of ICUs, they are nevertheless costlier than nursing units. Even if these changes could be made and more ICU or HDU resources became available, the problem of early recognition and appropriate response to deteriorating patients on general nursing units would remain.

Can this problem be remedied or at least improved by use of METs? Several studies have described ICU outreach implementation in hospitals, usually with use of historical controls because of the difficulties of prospective randomization (Table I). There are variations in the duration of MET implementation and control periods, and in the daily availability (12-24 hours) of the team. Team composition in these studies ranged from nurses alone through junior doctors and a critical care nurse, an ICU fellow and a nurse, ${ }^{1}$ or a variable configuration. Activities examined included response to call criteria, cardiac arrest attendance and length of followup of after ICU discharge. Interventions

Table 1: Reports on the efficacy of critical care outreach with a medical emergency team (MET)

\begin{tabular}{|c|c|c|c|c|}
\hline Trial & Setting & Design & Study results & Significance \\
\hline $\begin{array}{l}\text { Buist et al } \\
2002 \dagger\end{array}$ & $\begin{array}{l}\text { 300-bed tertiary } \\
\text { care hospital }\end{array}$ & $\begin{array}{l}\text { Pre-post } \\
\text { comparison }\end{array}$ & $\begin{array}{l}\text { Reduced cardiac arrests, from } 3.77 \text { to } 2.05 \text { per } 1000 \text { admissions; } \\
\text { after case-mix adjustment, a } 50 \% \text { reduction in unanticipated events }\end{array}$ & $p<0.001$ \\
\hline $\begin{array}{l}\text { Bellomo et al } \\
2003,2004 \S\end{array}$ & $\begin{array}{l}\text { Tertiary care } \\
\text { hospital }\end{array}$ & $\begin{array}{l}\text { Pre-post } \\
+ \text { seasonal } \\
\text { controls }\end{array}$ & $\begin{array}{l}\text { Decrease in cardiac arrests, from } 63 \text { (seasonally adjusted 51) to } 22 \\
\text { Decrease in in-hospital deaths, from } 302 \text { (adjusted 275) to } 222 \\
\text { Fewer postoperative complications and deaths }\end{array}$ & $\begin{array}{l}p<0.001 \\
p=0.018 \\
p<0.001,<0.018\end{array}$ \\
\hline $\begin{array}{l}\text { Hillman } \\
\text { (MERIT) } \\
20059\end{array}$ & $\begin{array}{l}23 \text { tertiary care } \\
\text { and community } \\
\text { hospitals }\end{array}$ & $\begin{array}{l}\text { Cluster- } \\
\text { randomized } \\
\text { controlled }\end{array}$ & $\begin{array}{l}\text { Decrease in cardiac arrests in control as well as test groups } \\
\text { No significant between-group decreases in cardiac arrests or } \\
\text { ICU admissions }\end{array}$ & $\begin{array}{l}p=0.003 \\
p=0.74 \\
p=0.60\end{array}$ \\
\hline
\end{tabular}

Note: $\mathrm{DNR}=$ do not resuscitate, ICU = intensive care unit, $\mathrm{HDU}=$ high-dependency unit, $\mathrm{RR}=$ relative risk.

*Med J Aust 2000;173:236-40.

†BMJ 2002;324(7334):387-90.

$\mp B M J$ 2003;327(7422):1014-7. This study was done in the United Kingdom; all others took place in Australian hospitals.

§Med J Aust 2003;179:283-7 and Crit Care Med 2004;32:916-21.

ILancet 2005;365(9477):2091-7 [erratum, 2005;366(9492):1164] 
Table 2: Call criteria* for the Rapid Assessment of Critical Events (RACE) in-hospital critical care outreach system

\begin{tabular}{|c|c|}
\hline Vital sign & Indications \\
\hline Airway & Threatened airway, excessive secretions or stridor \\
\hline Breathing & Respiratory rate $\leq 8$ or $\geq 30$ breaths $/ \mathrm{min}$ \\
\hline Circulation & $\begin{array}{l}\text { - Systolic blood pressure } \leq 90 \text { or } \geq 200 \mathrm{~mm} \mathrm{Hg} \text {, or a drop } \geq 40 \mathrm{~mm} \mathrm{Hg} \\
\text { - Heart rate } \leq 40 \text { or } \geq 130 \text { beats } / \mathrm{min}\end{array}$ \\
\hline Consciousness & Decreased (Glasgow Coma Scale $>2$ ) \\
\hline $\mathrm{O}_{2}$ saturation & $<90 \%$ with patient receiving $6 \mathrm{~L} / \mathrm{min}$ or $50 \%$ oxygen supplementation \\
\hline Urine output & $<100 \mathrm{~mL}$ over 4 -hour period \\
\hline $\begin{array}{l}\text { General } \\
\text { condition }\end{array}$ & $\begin{array}{l}\text { - A health care worker is "worried" about patient } \\
\text { - Patient needs medical assistance } \\
\text { - Patient fails to respond to treatment }\end{array}$ \\
\hline
\end{tabular}

*Activation criteria as used in most Ottawa hospitals. Any of the indications listed is reason to call the team. included such procedures as tracheostomy care; intubation; physiotherapy; diuretic, vasopressor and, analgesic therapy; intravenous fluid resuscitation; medical consultations; noninvasive positive-pressure ventilation; laboratory and imaging investigations; and oxygen therapy. Most studies (especially those with lengthier implementations) reported improvements, including fewer cardiac arrests, longer survival after an arrest, fewer postoperative complications (e.g., respiratory failure, stroke, severe sepsis, acute renal failure, myocardial infarction, pulmonary embolism, ICU readmission and death) and reduced rates of in-hospital death and unanticipated ICU or HDU admission. The most recent study of critical care outreach (Table I), in which METs were introduced concurrently in I2 Australian hospitals (with II others serving as controls), failed to demonstrate significant reductions in numbers of cardiac arrests or ICU admissions. Possible reasons may have been that the study lasted only 6 months, had low utilization of call criteria and may have undergone cross-contamination between the 2 study groups. Thus, to date, evaluation results of METs have been mixed. These studies suggest substantial potential benefits to the MET approach, but implementation for a year or longer may be necessary to demonstrate them.

Better use of routinely observed vital signs and rapid evaluation of high-risk patients by a team skilled in the care of critically ill people (i.e., a team similar to the cardiac arrest, trauma and stroke teams already present in many institutions) ought to reduce rates of patient morbidity and death. The intent is to identify these patients before a crisis, with early intervention to prevent respiratory, circulatory and other failure, ICU admission and cardiac arrest. No construction costs are incurred and less equipment is required. Staffing a team is less costly than staffing an HDU, and team members may be available for other duties when not responding to MET calls. Enthusiastic and committed team members (physicians, nurses and perhaps respiratory therapists and physiotherapists) are essential, with buy-in from hospital administrators, nurses and physicians. In teaching hospitals, METs are ideal for teaching acute resuscitation under supervision.

The most important member of the team is the bedside nurse. Intensive and repeated education is necessary to change both the way vital signs are used and the usual consultation process.

How does this system work to identify patients at risk? Deteriorating patients can be identified with the use of simple screening tools, several variations of which have been published. Nurses monitoring patients on the general nursing units record physiologic parameters such as heart and respiratory rates, blood pressure and mental status. Some systems specify thresholds to trigger a call for assistance (e.g., Table 2), whereas others are more complex and use an aggregate score from several parameters (e.g., Table 3). The vaguely defined but valuable "concern" or "worry" of the experienced practitioner is also often included (Table 2). In addition, the outreach team may follow up with patients recently discharged from the ICU.

Although common in Australia and the United Kingdom, the emergence of ICU outreach teams in Canada has been limited and recent. Some hospiintroducing critical care outreach with the Canadian Collaborative to Improve Patient Care and Safety in ICU (www .improvementassociates.com). The Ottawa and Toronto outreach programs are also developing educational modules for staff training.

Many questions remain to be answered. Is critical care outreach necessary in Canada? Although the Canadian health care system is different from systems in Australia and UK, anecdotal experience would suggest that the types of problems that can be addressed by outreach teams also exist here. Can METs be cost-effectals (e.g., in Calgary and Winnipeg) are

Table 3: Scoring for the Critical Care Outreach Team call criteria: Call if score $\geq 3$

\begin{tabular}{|c|c|c|c|c|c|c|c|}
\hline Scoring category & 3 & 2 & 1 & 0 & 1 & 2 & 3 \\
\hline Heart rate, beats/min & $<40$ & $41-50$ & - & $51-100$ & $101-110$ & $111-129$ & $\geq 130$ \\
\hline $\begin{array}{l}\text { Respiratory rate, } \\
\text { breaths/min }\end{array}$ & $\leq 8$ & - & - & $9-14$ & $15-20$ & $21-29$ & $\geq 30$ \\
\hline Temperature, ${ }^{\circ} \mathrm{C}$ & $<35$ & - & - & $35-38.4$ & - & $38.5-39$ & $>39$ \\
\hline $\begin{array}{l}\text { Systolic blood } \\
\text { pressure, } \mathrm{mm} \mathrm{Hg}\end{array}$ & $<80$ & $81-90$ & $91-100$ & $101-199$ & - & - & $\geq 200$ \\
\hline $\begin{array}{l}\text { Central nervous } \\
\text { system }\end{array}$ & - & - & - & Alert & $\begin{array}{l}\text { Responds } \\
\text { to voice }\end{array}$ & $\begin{array}{l}\text { Responds } \\
\text { to pain }\end{array}$ & $\begin{array}{c}\text { Un- } \\
\text { conscious }\end{array}$ \\
\hline Urine, $\mathrm{mL} / \mathrm{h}$ & Nil & $<20$ & - & - & - & - & $>400$ \\
\hline
\end{tabular}

Source: Adapted from Riley B, Faleiro R. Br J Anaesth 2001;1(CEPD Reviews, Suppl 5):146-9, with permission. 
tive in the Canadian health care system? What are the most effective and valid call criteria? What is the best model? The answers to these questions will probably vary from institute to institute. I encourage more hospitals to experiment with their own critical care outreach teams and evaluate their performance.
Alan D. Baxter

Department of Anesthesia and Critical Care

The Ottawa Hospital

Ottawa, Ont.

Competing interests: None declared.

\section{REFERENCES}

I. Lee A, Bishop G, Hillman KM, et al. The medical emergency team. Anaesth Intens Care 1995;23:183-6.

2. Schein RMH, Hazday N, Pena M, et al. Clinical an tecedents to in-hospital cardiopulmonary arrest. Chest 1990;98:1388-92.

3. McGloin H, Adam SK, Singer M. Unexpected deaths and referrals to intensive care of patients on general wards. Are some cases potententially avoidable? JR Coll Physicians Lond 1999;33:255-9.

\section{Canada Diagnostic Centres} Revolution in Non-Invasive
Coronary Artery Disease Diagnosis State-of-the-art 64-detector CT Makes Coronary CT Angiography a Reality

Minimally Invasive: Outpatient procedure requiring no sedation Cardiologist \& Radiologist Partnership: Patients benefit from both specialties

Maximum Information: Detailed images of coronary arteries, plaque and arterial wall

Clinical Indications for Coronary CT Angiography (CCTA)

- Atypical chest pain in a patient at risk for coronary artery disease (CAD)

- Clarification of inconclusive non-invasive studies, e.g. stress tests

= Screening in high risk individuals when soft plaque is suspected

- Interval evaluation of known CAD, in patients who have indeterminate symptoms

- Evaluation of bypass grafts and stents

- To exclude CAD in patients with impaired left ventricular function
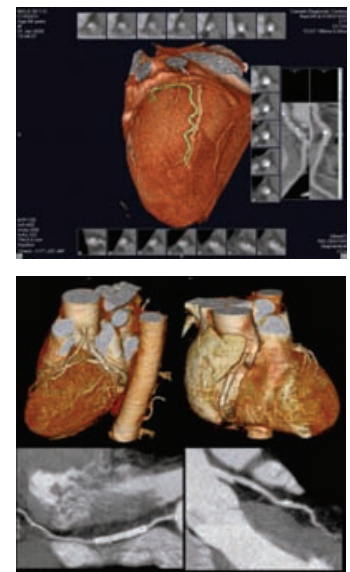

For more information on CCTA, visit www.CanadaDiagnostic.com \#136 - 555 W 12th Avenue, Vancouver, B.C. V5Z 3X7 | Toll Free 1-877-709-8522 | Tel 604-709-8522 | Fax 604-709-6112 